\title{
O elogio de si e a desmedida antropologização das ciências humanas
}

\author{
Marcos Villela Pereira \\ Pontifícia Universidade Católica do Rio Grande Do Sul \\ Cleber Gibbon Ratto \\ Centro Universitário Metodista
}

\section{Resumo}

Este trabalho faz a crítica filosófica a um certo modo de antropologização nas ciências humanas. 0 humano não é um dado natural de determinação biológica no campo das ciências. Diferente disso, o específico do conhecimento no campo das humanidades é o resultado de um processo de antropologização que fez do homem sujeito com consciência epistemológica. Por isso, o homem, figura de proa da modernidade, é esse duplo empírico-transcendental que, dobrado sobre si mesmo, produz um regime próprio de saber. Conhecimento de si, portanto, passou a ser a grande matriz dos saberes das humanidades na proporção equivalente em que a metafísica se transfigurou em metafísica da subjetividade e a linguagem ganhou prestígio ontológico. Ao lado disso, ergueu-se boa parte dos projetos de crítica à ciência clássica, dando lugar de destaque à linguagem como fabricante de realidade. Chegou-se a falar de um giro linguístico, argumento primeiro de crítica às metanarrativas e apologia dos regimes fragmentários e relativistas de verdade. Ainda assim, assumir que a verdade é um efeito discursivo e que a realidade por si mesma é resultado de uma produção não é o bastante. Importa também colocar em exame este regime que fez da linguagem a expressão do conhecimento e da consciência do mundo. 0 homem tornou-se a medida do conhecimento.

\section{Palavras-chave}

Ciências humanas - Subjetividade - Antropologia - Linguagem Comunicação. 


\title{
Self-praise and the inordinate anthropologization of human sciences
}

\author{
Marcos Villela Pereira \\ Pontifical Catholic University of Rio Grande Do Sul \\ Cleber Gibbon Ratto \\ Methodist University Center
}

Contact:

Marcos Villela Pereira

Rua La Plata, 980 ap. 601

90.670-040 - Porto Alegre - RS

E-mail: marcos.villela@pucrs.br

\section{Abstract}

The present work conducts a philosophical critique of a specific form of anthropologization of the human sciences. The human is not a biologically determined natural fact within the field of the sciences. Quite differently, the specific to the field of the humanities is the outcome of a process of anthropologization that made man a subject endowed of epistemological conscience. For this reason, man, center stage figure of modernity, is this empirical-transcendental double who, bent over himself, produces his own regime of knowledge. Knowledge of oneself, therefore, became the big matrix of the humanities knowledge, in the same proportion that metaphysics was transmuted into metaphysics of subjectivity, and language acquired ontological prestige. Along these lines, a large share of the projects of criticism to classical science was erected, conferring pride of place to language as the manufacturer of reality. There was even mention of a linguistic turn, a prime argument of critique to the metanarratives and eulogy of the fragmentary and relativist regimes of truth. Still, to assume that truth is a discursive effect, and that reality by itself is the outcome of a production, is not enough. It is also important to examine this regime that turned language into the expression of knowledge and of the conscience of the world. Man has become the measure of knowledge.

\section{Keywords}

Human sciences - Subjectivity - Anthropology - Language Communication. 
Este trabalho faz a crítica filosófica a um certo modo de antropologização nas ciências humanas. 0 humano não é um dado natural de determinação biológica no campo das ciências. Diferente disso, o específico do conhecimento no campo das humanidades é o resultado de um processo de antropologização que fez do homem sujeito com consciência epistemológica. Por isso, o homem, figura de proa da modernidade, é esse duplo empírico-transcendental que, dobrado sobre si mesmo, produz um regime próprio de saber. Conhecimento de si, portanto, passou a ser a grande matriz dos saberes das humanidades na proporção equivalente em que a metafísica se transfigurou em metafísica da subjetividade e a linguagem ganhou prestígio ontológico. Ao lado disso, ergueu-se boa parte dos projetos de crítica à ciência clássica, dando lugar de destaque à linguagem como fabricante de realidade. Chegou-se a falar de um giro linguístico, argumento primeiro de crítica às metanarrativas e apologia dos regimes fragmentários e relativistas de verdade. Ainda assim, assumir que a verdade é um efeito discursivo e que a realidade por si mesma é resultado de uma produção não é o bastante. Importa também colocar em exame este regime que fez da linguagem a expressão do conhecimento e da consciência do mundo. 0 homem tornou-se a medida do conhecimento.

Adentramos a modernidade tentando encontrar uma estratégia para escapar do constrangimento da Idade Média: tratava-se de constituir uma nova episteme para a organização dos saberes e de alguma alternativa ao dogmatismo da moral cristã.

A modernidade é definida, entre outras coisas, pelo advento da razão esclarecida, constituída sistematicamente em movimentos culturais, políticos e intelectuais desde o século XVI, em que o sujeito se pensa como o centro principal de referência de qualquer verdade sobre o que existe. Nesse tempo, a razão pretendeu-se ordem e medida de todas as coisas, trabalhou pelo estabelecimento de uma forma hegemônica de constituição da verdade e assegurou os princípios da lógica como paradigma único e absoluto.

Sistematicamente, o mundo moderno postulou a razão universal como essência do humano, condenando equivocadamente o homem ao trabalho de Sísifo de encontrar e revelar a verdade das coisas. E tornou-se tarefa insana a busca pela verdade e a corrida atrás de estratégias argumentativas que assegurassem a perfeita coincidência entre aquelas duas substâncias que Descartes fez o favor de estipular: a res extensa e a res cogitans, a aparência e a essência. A partir disso, acreditou-se que havia uma verdade a ser descoberta e revelada e que o caminho para isso era a razão, entendida como a grande luz que tudo ilumina e esclarece. Entretanto, ao trabalhar imersa na ilusão da possibilidade de um único paradigma, a razão moderna trabalhou por corroer a solidez das verdades dogmáticas e plantar no homem a faculdade de julgar e decidir o que é verdadeiro ou falso, certo ou errado, bom ou mau, belo ou feio, justo ou injusto. A modernidade, assim, corresponde a sucessivos movimentos de estabelecimento e derrubada de verdades sobre o que existe, uma incessante busca por um método universal que resultasse na revelação da verdade eterna sobre o mundo. E tudo passou a ser orientado dessa maneira, inclusive o conhecimento moral.

A razão prática vasculha a realidade e produz diferentes formas de racionalidade: vai tentando converter a realidade em um conjunto de coisas explicáveis, compreensíveis, justifıcáveis, em resumo, em uma moral. Tudo o que existe (e mesmo o que não existe) é submetido a um crivo racional que vai tentar nomear, dizer, pensar, julgar. Qualquer outra forma de ordenação ou de juízo torna-se alvo de sanção porque representa outra coisa que não aquela forma dominante. E o ataque que a razão faz pressupõe que essa forma negue a universalidade da razão. Ou seja, formas de relação com o mundo (como a intuição, percepção, sensação 
ou qualquer outra) só são admitidas se obedecerem a uma ordem que as acabe por converter em formas de racionalidade.

Viver é pensar e pensar é exercitar a razão e, portanto, seguir certas ordens, ser racional. Durante muito tempo buscou-se exercitar a razão no sentido de ampliar as formas de entendimento de tudo o que há, fazendo com que ela não apenas se explique a si mesma como também dê conta de explicar aquilo que a ultrapassa. Como se tudo, mesmo o que esteja fora da razão, supostamente fora de seu alcance, terminasse por caber em seu esquadro. Quando sobreveio a ideia da emancipação, da razão iluminista insuflando o ideal emancipatório, a modernidade empurrou o sujeito para a necessidade de se emancipar pelo esclarecimento, pela ilustração, pelo estabelecimento de uma verdade e uma moral, ela também emancipatória. E a razão, crivo de tudo o que passa pelo pensamento, foi quem capitaneou esse ideal (PEREIRA, 2008).

Enfım, a modernidade é coroada com uma ideia de "formação" que se entende como uma transformação da alma e do espírito que supostamente capacita o homem para participar na determinação da verdade no mundo e na vida. Ou seja, as virtudes são reduzidas a formas de racionalidade que devem regular a vontade e o sentimento. A perspectiva da formação (no sentido da Bildung) é levar o homem a realizar uma elevação do particular ao universal, um aprimoramento do seu saber pela universalização. A razão, ao agir sobre as coisas à sua volta, ao formar a realidade, forma a si mesma.

Portanto, conhecimento, habilidades e moral são alinhados sob uma perspectiva universalizante que deve perseguir uma verdade única. E o sujeito, por consequência, como encarnação dessa consciência universal, torna-se um sujeito transcendente. A formação obedece a essa tarefa de transformar o homem em um sujeito ideal: as particularidades da experiência devem ser elevadas ao universal.
A crise que sobrevém à modernidade resulta da constatação de que o mundo não é racional. A razão é uma condição humana. E o mundo simplesmente acontece, ele não cessa de se arranjar, não para de acontecer, não para de existir. E a razão acaba ficando em defasagem um instante após o mundo ir se arranjando. 0 mundo vai acontecendo, as coisas vão sendo, e isso tudo que acontece e existe é como uma amostra da sua sustentabilidade, do jeito que as coisas são e conseguem ser, mesmo quando não cabem na razão. As coisas são o que podem ser. As coisas não são o que querem ser ou o que devem ser. Não há uma "razão" transcendental que ordena o mundo. E como a plasticidade da razão é uma coisa que vai se produzindo com o tempo, parece que o mundo resiste à razão. E o esclarecimento, portanto, revela-se como a ilusão do conhecimento universal: não há razão (como condição humana) que dê conta do mundo. 0 mundo não cabe na razão, a realidade não cabe no pensamento.

Adentramos no século XX descobrindo que $o$ paradigma era $u m$ paradigma, que $o$ método era $u m$ método e que $a$ verdade era uma verdade. Em suma, no século XX, alcançamos ver que a Razão (com ' $\mathrm{R}$ ' maiúsculo) era uma forma de racionalidade e que o homem não tinha por trás (ou por dentro ou no fundo) nenhuma essência que o antecedesse. Deparamo-nos com a constatação de que o ato de conhecimento, longe de constituir-se como o acesso à verdade, é uma experiência de construção de uma verdade.

Dessa maneira, temos nas mãos, como resíduo dessa análise, a ideia de que a realidade não tem uma verdade ou um sentido em si, já que se desfaz a possibilidade de alguma instância metafísica ou essencial que assegure a permanência das supostas formas universais do pensamento sobre o mundo. Temos diante de nós uma realidade que resulta de um sentido que lhe é atribuído pelo sujeito que a experimenta. Uma realidade, como diz Bauman (2001), líquida, que se conforma segundo uma forma de racionalidade que sobre 
ela se debruça. Não mais uma única forma de racionalidade, uma razão universal, mas uma realidade que se produz na própria experiência do sujeito, que, ao existir, fabrica diferentes formas de racionalizar o mundo.

Segundo Wolfgang Welsch (2007, p. 251), “estruturas da racionalidade são sempre associadas com práticas culturalmente compartilhadas e, inversamente, culturas podem ser concebidas como formas de racionalidade". Diferentes culturas correspondem a diferentes formas de racionalidade, a diferentes paradigmas. Paradigmas não são construções abstratas alheias à condição histórica ou política, não são pressupostos universais ou princípios absolutos. Antes, paradigmas são formas de racionalidade cultural, histórica e politicamente construídas. Referindo-se à compreensão a que chegamos no século XX, ele diz que

[...] não existe, de agora em diante, mais nenhuma pergunta que não seria respondida de forma diferente por diferentes paradigmas. [...] A validade das constatações feitas no interior de uma versão de mundo é relativa às premissas dessa versão: no contexto das premissas escolhidas, as afirmações fazem sentido; no contexto de outras premissas, não. (WELSCH, 2007, p. 251)

Essa ideia de que a verdade sobre o mundo corresponde a um sentido produzido no contexto de uma determinada experiência nos conduz a uma condição de pluralismo, de relativismo, que nada tem de permissivo ou leviano, como tentaram nos fazer crer os arautos do apocalipse pós-moderno. Diferentemente, esse relativismo exige de nós um debate crítico sério, que nos coloque frente a frente com a nossa própria cultura, nossa própria história e com o nosso próprio exercício de racionalização. Longe de nos levar na direção de um relativismo absoluto (isso, aliás, é efeito de um pensamento absolutista), Welsch leva-nos na direção do que ele chama de "relativismo esclarecido", um exercício de autocrítica no interior de uma realidade transcultural (WELSCH, 2007, p. 250). A que ordens filosóficas ou políticas nos alinhamos? Que escolhas fazemos para a humanidade e para o mundo? Que olhar constituímos sobre a realidade, sobre os outros e sobre nós mesmos? De que cultura nos encharcamos?

Diante do desconforto e da insegurança produzidos pelo fato de que uma mesma ideia pode ser verdadeira em um certo contexto e ser falsa em outro, diante da incerteza diante do que existe e suas implicações no que ainda virá a existir, diante do pluralismo de sentidos, somos tentados (por aquele modelo de racionalidade universal) a grudar sobre a realidade uma impossível capa metafísica invariável. Porém, é o exercício da crítica, da autocrítica, que nos permite escapar dessa ilusão e conhecer, compreender e demarcar as diferentes formas de racionalidade possíveis implicadas na nossa experiência do mundo. Disso só é capaz o homem dotado de razão e linguagem.

0 nascimento do homem com consciência epistemológica, simultaneamente condição e objeto do conhecimento, faz que a linguagem assuma uma função ainda mais drástica, dizer a verdade do "Eu". A linguagem comete uma loucura, como sugere Nietzsche. "Bela loucura a da linguagem: graças a ela o homem baila sobre todas as coisas" (NIETZSCHE, 2000, p. 259). E agora, modernamente, pretende bailar sobre ele mesmo. Isso só pode se dar no solo positivo da episteme moderna.

Os temas modernos de um indivíduo que vive, trabalha e fala segundo as leis de uma economia, de uma filologia e de uma biologia, mas que, por uma espécie de torção interna e de superposição, teria recebido, pelo jogo dessas próprias leis, o direito de conhecê-las e de colocá-las inteiramente à luz, todos esses temas, para nós familiares e ligados à existência das "ciências humanas" são excluídos pelo pensamento clássico: não era possivel naquele tempo que se erguesse, no limite do mundo, essa estatura estranha de um ser cuja natureza (a que determina, 
o detém e o atravessa desde o fundo dos tempos) consistisse em conhecer a natureza e, por conseguinte, a si mesmo como ser natural. (FOUCAULT, 2002, p. 428)

Aqui interessa de modo especial esse lugar privilegiado que a linguagem vai ocupando nas ciências humanas, como instrumento de conhecimento e comunicação do mundo. $\mathrm{E}$, de modo ainda mais particular, interessa a palavra que comunica a respeito de si, a palavra autorreferente. Porque o que caracteriza as ciências humanas não é meramente a presença do homem como tema, mas o modo como o homem opera a linguagem para produzir "consciência" daquilo que lhe foge, que lhe escapa. 0 homem vira medida do mundo. E a experiência mundana vai sendo ofuscada pela supremacia da linguagem fazedora de consciência.

0 que manifesta, em todo caso, o específico das ciências humanas, vê-se bem que não é esse objeto privilegiado e singularmente nebuloso que é o homem. Pela simples razão de que não é o homem que as constitui e lhes oferece um domínio específico; mas, sim, é a disposição geral da episteme que lhes dá lugar, as requer e as instaura - permitindo-lhes assim constituir o homem como seu objeto. Dir-se-á, pois, que há "ciência humana" não onde quer que o homem esteja em questão, mas onde quer que se analisem, na dimensão própria do inconsciente, normas, regras, conjuntos significantes que desvelem à consciência as condições de suas formas e de seus conteúdos. (FOUCAULT, 2002, p. 504)

E não se trata do "inconsciente" na forma que convencionalmente lhe atribuem as psicanálises. Inconsciente aqui seria

[...] justamente essa região que não se expressa em palavras, o domínio que escapa à linguagem. Não é, pois, por acaso, que não tratamos do inconsciente em Nietzsche; além de não existir aí enquanto conceito, o que se poderia chamar eventualmente de inconsciente remete, de imediato, ao indizivel. (MARTON, 2001, p. 181)

Inconscientes seriam todas as forças vivas do mundo que não cabem na linguagem.

A linguagem, então, será tomada aqui como a expressão sempre reencenada de um narcisismo primário. Uma vontade duração, de ordem, de aquietamento identitário.

Corroborando a hipótese de Marshall McLuhan (1967, 1974), assume-se que as pautas de compreensão sociais entre os homens dependem diretamente da linguagem e das práticas comunicativas, de modo que são sempre autoplásticas. As relações de comunicação proporcionam uma espécie de redundância na qual se pode vibrar e reconhecer como grupo. Elas dão os ritmos e os modelos a partir dos quais os grupos humanos se reconhecem e com os quais se reproduzem.

As linguagens são instrumentos de narcisismo de grupo; se tocam para afinar e voltar a afınar os instrumentistas; permitem aos falantes soar em tons idiossincráticos de autoexcitação; são sistemas melódicos dirigidos ao reconhecimento que, na maioria dos casos, também representa a totalidade da mensagem; seu uso principal não tem a ver com o que na atualidade se denomina transmissão de informação, senão com a formação de corpos grupais comunicativos. (SLOTERDIJK, 2005, p. 13, tradução nossa)

É assim que a linguagem passa a funcionar na modernidade. Cumprindo sua vocação primitiva de ordenadora do mundo, dá ao homem a possibilidade de reconhecer-se cada vez mais ele mesmo, e a isso se dará aqui o nome de celebração eulógica da identidade.

Evidentemente a expressão desse narcisismo primário da linguagem assume formas diferentes a cada momento, e é exatamente uma 
de suas formas contemporâneas de expressão que se pretende aqui demarcar: a apologia da comunicação autorreferencial nas ciências humanas, e na educação, com finalidades de saber e formação, funcionando como força de exacerbação do individualismo e empobrecimento da experiência mundana.

Sloterdijk (2005) prossegue dizendo que

[...] os homens dispõem de linguagem para falar de suas próprias vantagens, entre elas - e não é a menos importante - dessa insuperável vantagem que é poder falar de suas próprias vantagens na sua própria linguagem. (p. 13)

A episteme moderna, tornando possíveis as ciências humanas, não só cria o homem como também lhe dá a linguagem e a comunicação autorreferente como possibilidade de reencenar continuamente sua própria identidade.

[...] Nesse sentido, toda linguagem, antes de converter-se em um procedimento técnico, permite a qualquer falante elevar-se e glorificar-se, e os discursos técnicos, ainda que de maneira indireta, não fazem outra coisa senão o elogio dos próprios técnicos. (SLOTERDIJK, 2005, p. 14)

0 homem ergue-se numa posição de vantagem em relação ao próprio mundo e faz da linguagem, por força da necessidade comunicativa, uma ferramenta de reiterada afirmação dessa vantagem.

Assim é que se põe o mecanismo que essa tese busca percorrer para demarcar. Uma incitação da necessidade comunicativa autorreferente eleva a linguagem em sua função constitutiva - narcisista-primária - a uma condição de prestígio. A produção de uma compulsão à comunicação, portanto, opera como importante ferramenta na consecução de uma política das identidades, com a qual se estabelece um primoroso controle sobre a vida - um biopoder. Fazer falar é uma importante estratégia das políticas de controle social nos dias de hoje. Fazer falar de si, ainda mais. Porque falar de si é erguer-se numa importante condição de vantagem em relação ao mundo.

Quem utiliza uma linguagem segundo sua genuína função constitutiva, isto é, narcisista-primária, expressa com seu discurso sempre o mesmo: ao falando não poderia acontecer nada melhor no mundo que ser precisamente ele ou ela mesma e provar isso nessa linguagem, e neste preciso lugar, o da vantagem de poder estar em sua própria pele. (SLOTERDIJK, 2005, p. 14)

Mas a extensão desse fenômeno nem sempre foi a mesma. É sobretudo no individualismo moderno e no esteticismo contemporâneo que vai ganhar uma força cada vez maior. Há toda uma história das formas assumidas por essa pretensão de vantagem sobre o mundo, e é exatamente do curso atual desse evento que aqui se quer tratar.

Desde uma perspectiva histórica, há que reparar no fato de que antes do narcisismo primário se converter, com a irrupção da modernidade, na senha de identidade de algumas nações tão absortas em seus clássicos como em suas armas, num primeiro momento este fenômeno só podia ser observado no âmbito étnico e entre a realeza. No que tange ao indivíduo, terá que passar algum tempo para que sua auto-afirmação adquirisse legitimidade para sair das sombras do pecado e aparecer como o amor-próprio no século XVIII, a sagrada busca do eu no XIX, o narcisismo no XX, e o auto-desenho no XXI. (SLOTERDIJK, 2005, p. 15)

Na ambiência da educação, o advento das histórias de vida de um modo geral, atreladas à pesquisa e às práticas de formação, parece colocar em cena "novas" modalidades de fontes e de tratamento. A linguagem ganha um lugar de destaque no exato momento 
em que é alvejado o "paradigma moderno" que durante muito tempo ditou as regras no campo do conhecimento. Se é levado a entender que todo esse desenvolvimento está fortemente implicado com uma ativação das fontes narrativas no campo das ciências humanas como um todo e que isso advém de um giro linguístico que acabou por afetar toda a discussão em torno do sujeito e suas formas de constituição.

Larrosa (2004) aponta que um giro linguístico nas ciências humanas é uma das principais razões para a importância atribuída à linguagem no pensamento contemporâneo. Esse giro estaria composto por três outros, que lhe tornam possivel a existência.

0 primeiro deles, um giro hermenêutico, segundo o qual o ser é impensável fora da interpretação. Com isso, posto que toda interpretação é linguística, o ser é impensável fora da linguagem. Este primeiro giro é herdeiro de toda uma tradição filosófica que deu à linguagem um peso ontológico, ou seja, filósofos que uniram o ser e a linguagem na ideia de interpretação.

O segundo, um giro semiológico. Tanto a construção como o significado de um texto são impensáveis fora de suas relações com outros textos. Sua dívida parece estar para com aqueles filósofos que propõem a linguagem não como mero reflexo da realidade, senão que é ela própria a construtora do real, na negociação com outros regimes de signos. Aqui passa a conceber-se a relatividade, a instabilidade e a produtividade intrínseca dos signos, o que levaria a conceber a verdade como um efeito de eficiência interpretativa dentro de um determinado sistema semiótico.

E, por fim, um terceiro. Um giro pragmático. A ideia de que o sujeito humano está num mundo em que o discurso funciona socialmente no interior de um conjunto de práticas discursivas. Sendo assim, o poder que atravessa o discurso afeta os modos narrativos e, como consequência, a produção de verdades.
Essas são as ideias principais a partir das quais se deu um giro linguístico na perspectiva das ciências humanas e passamos a reconhecer que o sujeito se constitui fundamentalmente pela linguagem, e que ela é uma das grandes, senão a maior, responsável pela constituição do que se é.

Quién somos como sujetos autoconscientes, capaces de dar un sentido a nuestras vidas y a lo que nos pasa, no está más allá, entonces, de un juego de interpretaciones. Lo que somos no es otra cosa que el modo como nos comprendemos; el modo como nos comprendemos es análogo al modo como construimos textos sobre nosotros mismos; y cómo son esos textos depende de su relación con otros textos y de los dispositivos sociales en los que se realiza la producción y la interpretación de los textos de identidad. (LARROSA, 2004, p. 14-15)

De hecho, el sentido de lo que somos o, mejor aún, el sentido de quién somos, tanto para nosotros mismos como para los otros, depende de las historias que contamos y que nos contamos $y$, en particular, de aquellas construcciones narrativas en las que cada un de nosotros es, a la vez, el autor, el narrador y el carácter principal, es decir, de las autobiografías, autonarraciones o historias personales. (LARROSA, 2004, p. 12-13)

Dado isso, não será difícil entender por que as disciplinas acadêmicas passam a se interessar por capitalizar todas essas formas de narrativa e submetê-las ao crivo da investigação. Numa sociedade da compulsão comunicativa, na qual os meios tecnológicos tornam cada vez mais fluida e "imaterial" a vida, as narrativas de si tornam-se rapidamente alvo de controle social. E que maneira mais adequada de estabelecer tal controle senão pela produção de um conhecimento especializado que regule tal produção?! (RATTO, 2007). 
O contágio da educação por essa proliferação narrativa e pela correlata valorização das fontes primárias, e ainda mais especificamente das narrativas orais, parece ter-se dado modernamente na década de 60 , com o advento dos princípios da educação permanente. Nóvoa (2004) oferece-nos um excelente fragmento como evidência da penetração dessas ideias no campo educacional e, de modo sumário, sua estratificação em certas "linhagens" de pesquisa mundo afora.

Esta inicia-se na transição dos anos 60 para os anos 70, referindo o sucesso que então conheceu o conceito de Educação Permanente. Ele era portador de uma crítica ao "modelo escolar", deslocando a formação de uma idade específica (a infância) para todas as idades da vida e de um lugar concreto (a escola) para um conjunto de espaços sociais e culturais. [...] No conjunto das "saídas" que esta reflexão foi tendo, vale a pena assinalar o aparecimento das "histórias de vida" e o seu desenvolvimento nos espaços de formação de adultos. A equipa de Pierre Dominicé, na Universidade de Genebra, de que Marie-Christine Josso fez parte, foi um dos pólos principais deste movimento nos países francófonos. Por uma via distinta, com origem em John Dewey e nas leituras que dele fez Donald Schön, também nos Estados Unidos da América se equacionavam as questões da experiência e da reflexão. Um pouco mais tarde, Mathias Finger e eu próprio, que tínhamos sido alunos de Pierre Dominicé no início dos anos 80, publicávamos em Portugal uma colectânea de textos, $O$ método (auto)biográfico e a formação, que reunia muitos dos autores de referência dos dois lados do Atlântico. (NÓVOA, 2004, p. 13)

0 prestígio das narrativas e sua ampla difusão nos espaços educativos de modo especial, tendo como correlata a crescente valorização das narrativas autorreferentes, das biografias e histórias de vida de um modo geral, responde a uma nova modalidade de controle social, operada na esteira de uma sociedade cada vez mais fluida e pautada pelo fascínio da linguagem e da consciência de $\mathrm{si}^{1}$.

Assim a dimensão "experiencial" e "narrativa” da formação ganha prestígio, assumindo-se de modo tácito que o conhecimento se dá pela progressiva e desejável consciência que o agente das práticas toma a respeito de si próprio. Trata-se do primado das práticas reflexivas, onde se reencena a cada prática a duplicação própria à produção do conhecimento no campo das ciências humanas. No dueto reflexão-ação encontra-se o sujeito com consciência epistemológica de sua prática, e esse mesmo sujeito que conhece se constitui como objeto desta consciência. Ele ocupa as duas posições: reflexão e ação, mediadas por indispensáveis narrativas de si próprio. Os saberes, portanto, passam a ser produzidos numa espécie de epistemologia da prática, modo característico e prestigiado das ciências humanas e de tão forte penetração nas pesquisas educacionais da atualidade.

Vale notar que, na educação em especial, dada sua "missão" como instância privilegiada de produção dos sujeitos morais, uma tal epistemologia acaba sendo de grande eficiência ético-política, pois se consegue fazer simultaneamente a pesquisa e a formação. E isso ao mesmo tempo revela o quanto a educação e as ciências humanas de um modo geral, apesar de todas as suas "inovações", funcionam na ordem discursiva moderna, que pretende fazer a um só tempo o homem do conhecimento e da moral. Assim, a eficiência dos discursos educacionais como operadores da modernidade ética e política dá-se por força de sua ampla penetração no cotidiano das vidas dos sujeitos, lá onde ela parece mais íntima e resguardada.

1. Deleuze (2003) faz uma referência bastante nítida à emergência de modalidades de controle social para as quais se precisa estar suficientemente atento. "É necessário bem vigiar os temas que nascem, que se desenvolverão dentro de quarenta ou cinqüenta anos e que nos explicam que 0 admirável seria fazer, ao mesmo tempo, a escola e a profissão. Será interessante saber qual será a identidade da escola e da profissão através da formação permanente, que é nosso porvir e que não implicará mais forçosamente o reagrupamento de escolares dentro de um meio de fechamento" (p. 299-300). 
O controle biopolítico opera de maneira sutil, não mais com a visibilidade ostensiva de recursos disciplinares, mas através de mecanismos que apelam para o exercício da consciência de si, que voluntária e habilmente se conforma à ordem discursiva vigente (RATTO, 2006).

Para muitas coisas servem os novos modos de fazer pesquisa e promover formação (sempre continuada), mas um efeito parece compartilhado por todos eles: o gerenciamento e controle da produção de verdades segundo parâmetros que na maioria das vezes sequer se sabe reconhecer quais são. Fazer falar parece ser uma marca bastante forte das novas modalidades de controle social. Substituem-se entusiasticamente as gramáticas com as quais são gestados academicamente os saberes, mas não se toca no cerne da questão: o atávico fascínio pela estabilização do mundo, que permitiria conhecê-lo e comunicá-lo.

A educação serviu aqui como um caso exemplar. De modo especial, nas quatro últimas décadas, acompanhamos um prestígio crescente da investigação das práticas e das narrativas atreladas aos projetos de formação. Fazer pesquisa e formação a um só tempo, tendo como matéria-prima as práticas e os relatos dos sujeitos. Daí resulta uma espécie de conhecimento que pretende se consolidar como "epistemologia da prática", num franco elogio à autorreferência. Eis o lugar-comum de um novo paradigma: todo conhecimento é autoconhecimento, toda formação é autoformação, toda prática é prática de si. Mas a que se refere esse "si"? Longe de ser uma redenção epistemológica que nos permitiria, talvez, desvendar o mundo como ele se dá na experiência particular de cada consciência, reduz o mundo à sua própria medida, a uma pessoalidade exacerbada. Dar lugar à subjetividade não é necessariamente driblar a vontade de soberania sobre o inaudito do mundo. Ao contrário, fazer da subjetividade a chave de sentido da ciência contemporânea acaba por resultar em mais um modo de redução da multiplicidade do mundo. A questão, para além da oposição entre objetividade ou subjetividade no trato da verdade, é o desafio de colocar em questão a forma antropológica. A pretensão humana do saber. Quanto a pretensão de ciência pode suportar um tanto de ignorância e de silêncio?

\section{Referências}

BAUMAN, Zygmunt. Modernidade líquida. Rio de Janeiro: Jorge Zahar, 2001.

DELEUZE, Gilles. Qu'est-ce que l'acte de création? In: Deux régimes de fous: 1975-1995. Paris: Minuit, 2003, p. 299-300.

FOUCAULT, Michel. As palavras e as coisas. São Paulo: Martins Fontes, 2002.

LARROSA, Jorge. Notas sobre narrativa e identidade. In: ABRAHÃO, Maria Helena Menna Barreto (Org.). A aventura (auto) biográfica: teoria e empiria. Porto Alegre: EDIPUCRS, 2004.

MARTON, Scarlett. Extravagâncias: Ensaios sobre a filosofia de Nietzsche. 2. ed. São Paulo: Discurso/UNIJUÍ, 2001.

MCLUHAN, Marshall; FIORE, Quentin. The medium is the massage: an inventory of effects. New York: Bantam Books, 1967.

MCLUHAN, Marshall. Os meios de comunicação como extensões do homem. Tradução de Décio Pignatari. 4. ed. São Paulo: Cultrix, 1974. 
NIETZSCHE, Friedrich. Assim falou Zaratustra. 11. ed. Tradução de Mário da Silva. Rio de Janeiro: Civilização Brasileira, 2000.

NÓVOA, António. In: JOSSO, Marie-Christine. Experiências de vida e formação. São Paulo: Cortez, 2004. Prefácio.

PEREIRA, Marcos V. Utopias contemporâneas para a vida coletiva. Disponível em: http://www.unioeste.br/prppg/mestrados/ letras/revistas/travessias/ed_002/cultura/utopiascomtemporaneas.pdf. Acesso em 27/06/2008.

RATTO, Cleber Gibbon. Compulsão à comunicação: modos de fazer falar de si. Educação \& Realidade, Porto Alegre, v. 31, n. 2., jul-dez. 2006

. Comunicação, estética e aprendizagem - impasses contemporâneos. REUNIÃO ANUAL DA ASSOCIAÇÃO NACIONAL DE PÓS-GRADUAÇÃO E PESQUISA EM EDUCAÇÃO - ANPED, 30. Anais. Caxambu, 2007.

SLOTERDIJK, Peter. Sobre la mejora de la Buena Nueva: el quinto "Evangelio" según Nietzsche. Traducción de Gérman Cano. Barcelona: Siruela, 2005.

WELSCH, Wolfgang. Mudança estrutural nas ciências humanas: diagnóstico e sugestões. In: Educação. Porto Alegre, ano XXX, n. 2 (62), p. 237-258, mai./ago. 2007.

Recebido em 04.09.09

Aprovado em 06.04.10

Marcos Villela Pereira é formado em Filosofia (UCPel) e doutor em Educação (Currículo) pela Pontifícia Universidade Católica de São Paulo (PUC/SP), com a tese Estética da professoralidade, um estudo interdisciplinar sobre a formação de professores. Professor titular e coordenador do Programa de Pós-graduação em Educação da Pontifícia Universidade Católica do Rio Grande do Sul (PUC/RS). Publicou artigos e trabalhos em torno do tema da formação e dos processos de subjetivação e desenvolve estudos filosóficos nesse campo. Atua nos cursos de graduação e pós-graduação em Educação, com ênfase nos fundamentos da educação. Coordenador do grupo de pesquisa "Cultura, Subjetividade e Políticas de Formação" (CNPq).

Cleber Gibbon Ratto é psicólogo pela Universidade Católica de Pelotas. Psicoterapeuta. Doutor em Educação pela Pontifícia Universidade Católica do Rio Grande do Sul (PUCRS), com a tese Compulsão à comunicação - ensaios de ética, educação e silêncio. Tem experiência nas áreas da Psicologia e da Educação, atuando principalmente nos temas ligados aos fundamentos filosóficos e sociológicos destas áreas. Discute temas como comportamento, comunicação, subjetividades contemporâneas, ética e estética. Coordenador do Curso de Psicologia do Centro Universitário Metodista (IPA), professor do Centro Universitário La Salle (UNILASALLE), professor convidado na Escola Superior de Propaganda e Marketing (ESPM). Integrante do grupo de pesquisa "Cultura, Subjetividade e Políticas de Formação" (CNPq). E-mail: cgratto@hotmail.com 